\title{
A Experiência do CBH-SMT no Pagamento por Serviços Ambientais
}

\author{
Kelly Cristina Tonello ${ }^{1}$ \\ Luiz Carlos de Faria ${ }^{2}$ \\ ${ }^{1}$ Prof ${ }^{\mathrm{a}}$. Universidade Federal de São Carlos, campus Sorocaba (UFSCar) \\ Coordenadora GTPSA-CBH-SMT \\ Rodovia João Leme dos Santos, Km 110 - SP-264, Bairro do Itinga \\ Sorocaba - São Paulo - Brasil, CEP 18.052-780 \\ kellytonello@ufscar.br \\ ${ }^{2}$ Prof. Universidade Federal de São Carlos, campus Sorocaba (UFSCar) \\ Rodovia João Leme dos Santos, Km 110 - SP-264, Bairro do Itinga \\ Sorocaba - São Paulo - Brasil, CEP 18.052-780 \\ lcfaria@ufscar.br
}

\begin{abstract}
This paper sets out the procedures adopted for the planning and operation of pilot payment for environmental services of Sorocaba and Middle Tietê watershed comittee. Are presented proposals aimed at its dissemination and enhancement, and support future initiatives compensation for forest conservation and restoration for the generation of environmental services.
\end{abstract}

Palavras-chave: Payments for environmental services, Water, Forest, Environmental Management

\section{Introdução}

O reconhecimento da importância dos serviços ambientais não é recente. Contudo, o conceito de pagamentos por serviços ambientais tem recebido considerável interesse nos últimos anos como uma forma de criar medidas de incentivo à gestão de recursos naturais nas propriedades rurais e formas de financiamento sustentável. A idéia básica é que aqueles que "fornecem" serviços ambientais, através da conservação dos ecossistemas naturais, devam ser compensados pelos beneficiários do serviço (WWF, 2006).

Os ecossistemas naturais fornecem uma ampla gama de serviços ambientais a partir do qual as pessoas se beneficiam, e sobre o qual toda a vida depende. Dentre estes benefícios, também chamados de serviços ecossistêmicos, destacam-se: a regulação do clima (seqüestro de carbono atmosférico pela vegetação), a formação de solos, ciclagem de nutrientes e proteção contra processos erosivos (serviços que favorecem as produções agrícola e pecuária), a proteção das áreas de recarga de recursos hídricos e a prevenção contra o aporte de poluição difusa que resulte em assoreamento de corpos d'água, a renovação de estoques pesqueiros, as paisagens naturais que viabilizam o ecoturismo e a provisão de produtos madeireiros e nãomadeireiros, entre outros (Constanza, 2005).

Fundamentalmente, a provisão de serviços ecossistêmicos depende da diversidade biológica, já que esta, junto com o componente físico local, compreende a essência de um ecossistema. Preservar e restaurar a biodiversidade, portanto, é essencial para que se restabeleçam os processos ecológicos essenciais e que os serviços ecossistêmicos sejam assegurados.

Neste contexto, uma política de pagamentos por serviços ambientais que estimule a conservação e restauração de florestas nativas, assim como o incentivo de sistemas produtivos de baixo impacto (por exemplo, agroflorestas e silvipastoris) contribuirão diretamente para preservação e recuperação da diversidade biológica local, além de mitigar os efeitos nocivos das mudanças climáticas através do sequiestro de carbono atmosférico. A recuperação da cobertura florestal, além de garantir maior proteção dos solos e minimizar perdas por erosão 
garantirá maior proteção aos recursos hídricos reduzindo o aporte de poluição difusa aos mesmos.

Na década de 1990, a cidade de Nova York implementou o "Watershed Agricultural Program (WAP)" para proteger seus mananciais. O programa promoveu a adoção de práticas ambientalmente sustentáveis para atividades agrícolas e demais usos do solo nas bacias hidrográficas no entorno da cidade. Os custos do WAP foram estimados em US $\$ 1,5$ bilhões, aproximadamente US $\$ 167$ milhões por ano. O custo da solução alternativa, construção de uma estação de tratamento da água, foi estimado entre US\$8 a US\$10 bilhões, aproximadamente US\$6 bilhões em infra-estrutura e outros US\$250 milhões anuais de manutenção.

A preservação e a recuperação dos benefícios que os serviços ecossistêmicos representam dependem, além da parcela que cabe ao governo, também da participação da sociedade. Não é suficiente a conservação dos remanescentes destes ecossistemas em unidades de conservação de domínio público, mas, os proprietários de terras em regiões onde os ecossistemas foram excessivamente reduzidos e fragmentados têm um papel preponderante nessa lógica. As tradicionais políticas de comando e controle adotadas no trato de questões ambientais não se mostram mais suficientes para garantir a conservação e restauração dos ecossistemas naturais e de seus serviços. A legislação ambiental, em especial o Código Florestal, contempla instrumentos para coibir o desmatamento, mas não prevê incentivos para que proprietários rurais tomem iniciativas de recuperar remanescentes de ecossistemas em suas terras, nem mesmo nas áreas consideradas de preservação permanente.

Neste sentido, faz-se necessária, uma política capaz de incentivar e mesmo induzir particulares a tomarem iniciativas para restaurar os ecossistemas e assegurar os benefícios prestados por estes à sociedade.

\section{O Comitê das Bacias Hidrográficas dos rios Sorocaba e Médio Tietê (CBH-SMT)}

O Comitê de bacias hidrográficas dos rios Sorocaba e Médio Tietê foi criado em agosto de 1995. Nessa época definiu-se que, dentre as 22 Unidades de Gerenciamento de Recursos Hídricos - UGRHI do Estado de São Paulo (Figura 1), o Tietê/Sorocaba seria identificado como UGRHI 10. O CBH-SMT localiza-se no centro-oeste do Estado de São Paulo, abrangendo um total de 53 municípios. Destes, 34 apresentam sede em seu território e os restantes possuem apenas porções rurais. A bacia do Médio Tietê compreende o trecho do Rio Tietê, desde o Reservatório de Pirapora até a Barragem de Barra Bonita, com extensão de 367 quilômetros e uma área de drenagem de 6.830 quilômetros quadrados. Os principais afluentes da margem direita são os rios Jundiaí, Capivari e Piracicaba. O principal afluente da margem esquerda é o Rio Sorocaba, formado pelos rios Sorocabuçu e Sorocamirim com suas cabeceiras localizadas nos municípios de Ibiúna, Cotia, Vargem Grande Paulista e São Roque. Ocupa uma área de drenagem de 5.269 quilômetros quadrados e percorre uma distância de 180 quilômetros em zona rural, desembocando no Rio Tietê no município de Laranjal Paulista. A área total da UGRHI 10 é de aproximadamente $11.800 \mathrm{~km}^{2}$, subdividida ainda em sub-bacias, compostas por drenagens de pequeno a médio porte: médio Tietê inferior, médio Tietê meio, baixo Sorocaba, Médio Sorocaba, Médio Tietê Superior e Alto Sorocaba (Figura 2). 


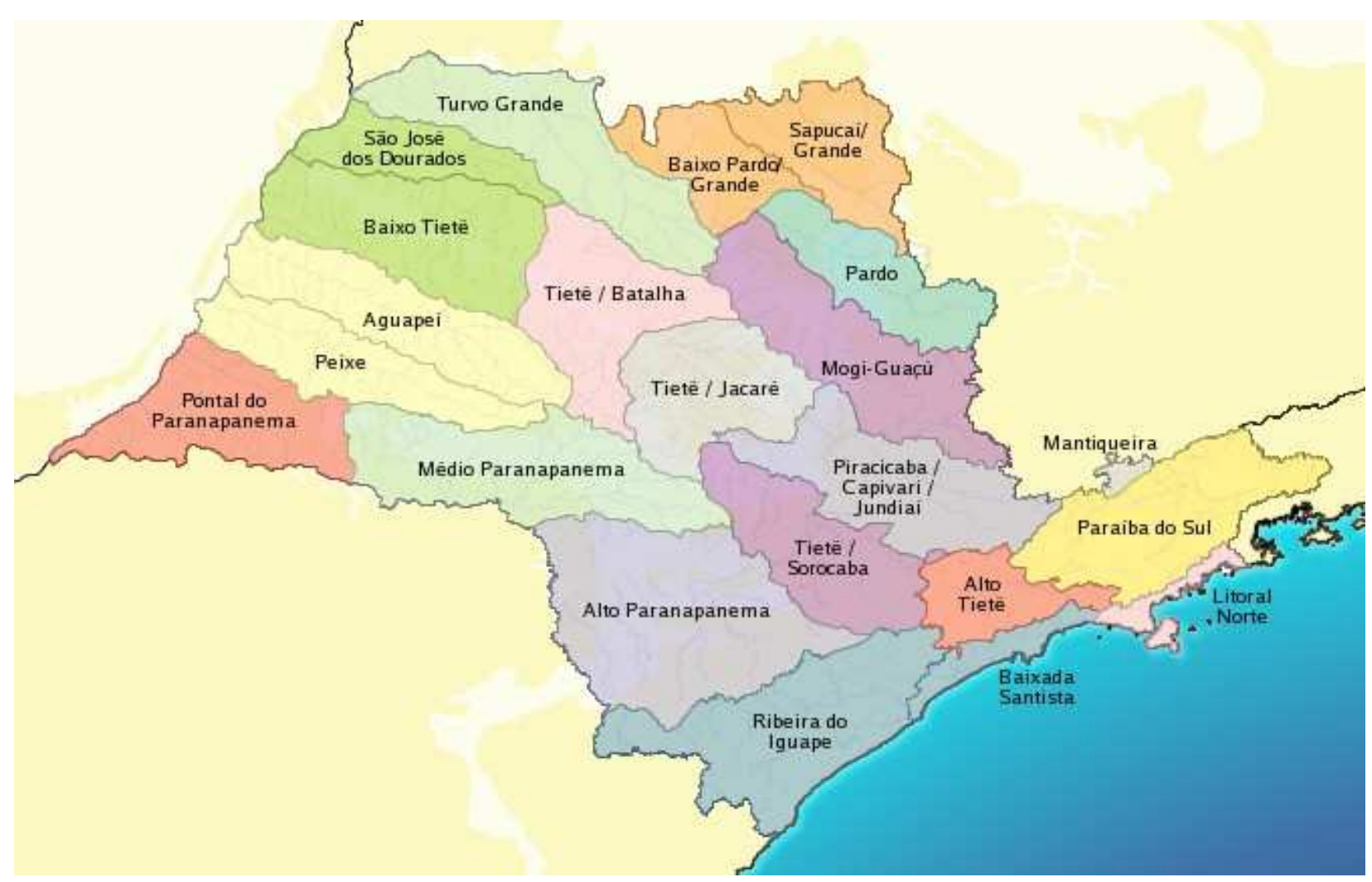

Figura 1. Divisão territorial dos Comitês de Bacias hidrográficas do Estado de São Paulo (Fonte: Rede das Águas).

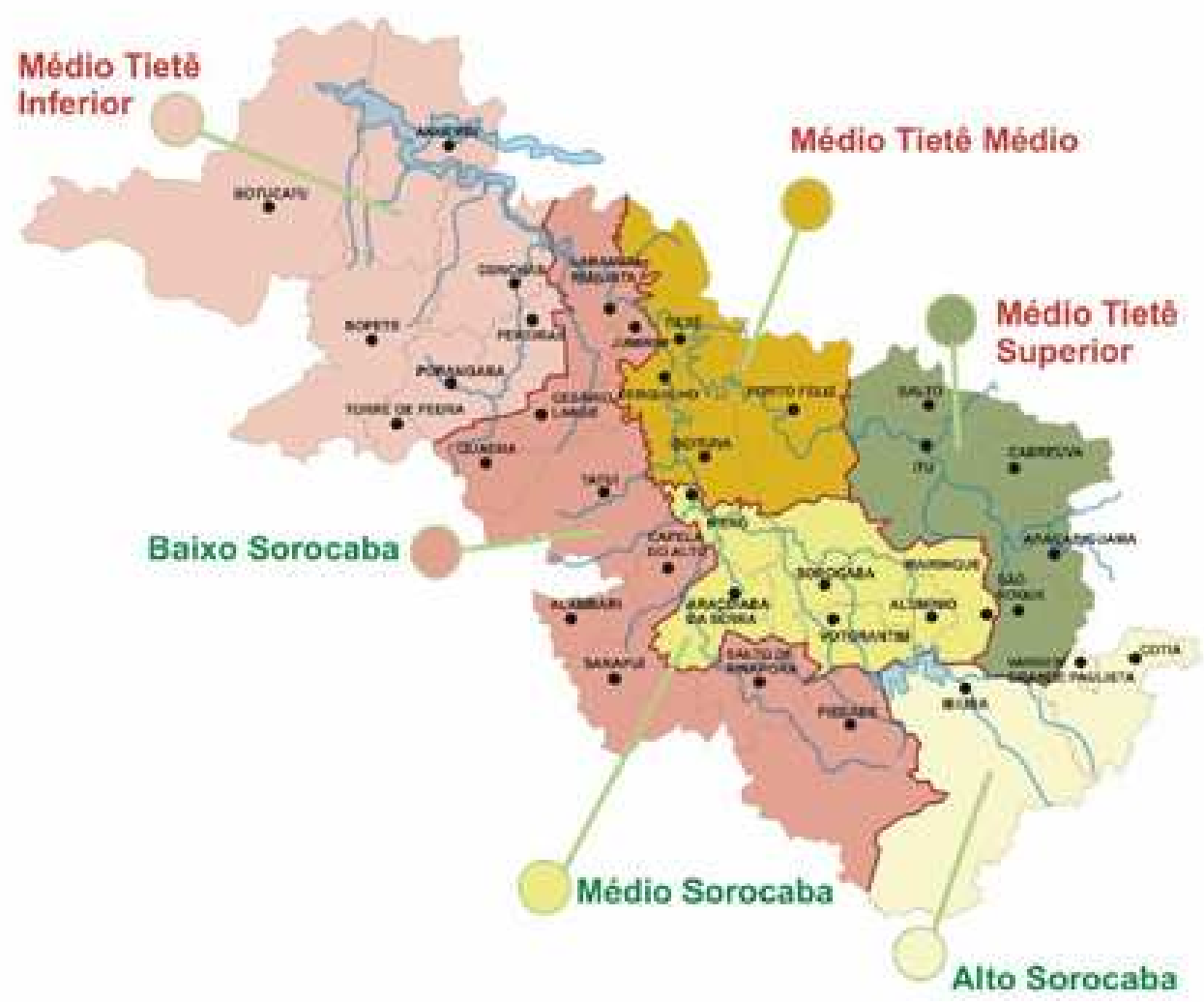

Figura 2. Localização das sub-bacias componentes da UGRHI 10 (Fonte: Rede das Águas). 


\subsection{Os Serviços Ambientais no âmbito do CBH-SMT}

O CBH-SMT promoveu, em março de 2009, o I Encontro sobre Serviços Ambientais juntamente com à Agência de Bacias e o apoio da Prefeitura Municipal de Sorocaba e do FEHIDRO. O encontro teve o objetivo de apresentar aos participantes projetos bem sucedidos que remuneram proprietários rurais que se preocupam em conservar áreas de mananciais (Pagamentos por Serviços Ambientais). O evento contou com a participação de professores da Universidade Federal de São Carlos/campus Sorocaba, Secretaria de Meio Ambiente dos municípios de São José dos Campos e Extrema, Fundação Boticário e The Nature Conservancy (TNC), os quais expuseram suas experiências e dúvidas relativas à questão. Após o evento houve uma grande demanda por informações sobre o tema na região, o que motivou a formação de um grupo de trabalho vinculado à Câmara Técnica de Planejamento para discussão do assunto no âmbito do CBH-SMT. A formalização Grupo Técnico sobre Pagamentos por Serviços Ambientais - GT-PSA ocorreu na $25^{\circ}$ Reunião do CBH-SMT, realizada em abril de 2009, no município de Cerquilho-SP. O objetivo do GTPSA é definir as estratégias para implantação e coordenar os programas para os pagamentos por serviços ambientais na bacia dos rios Sorocaba e Médio-Tietê.

Desde de então, o GT-PSA, composto por membros da sociedade Civil, Estado e Município, realiza reuniões periódicas a fim de estruturar um programa para o pagamento por serviços ambientais no CBH-SMT. O GT-PSA, já obteve alguns avanços importantes, como por exemplo, a decisão unânime de que o programa a ser desenvolvido pelo CBH-SMT abordará a questão "produtor de água". Definiu-se também que a microbacia do Ribeirão Murundú será a área piloto de implantação do programa por este ser um importante afluente do rio Sorocaba e componente da Área de Proteção Ambiental de Itupararanga.

\subsection{A escolha da área piloto}

\subsubsection{A relevância da Área de Proteção Ambiental de Itupararanga (APA Itupararanga)}

Há anos, os moradores dos municípios de Alumínio, Cotia, Ibiúna, Mairinque, Piedade, São Roque, Vargem Grande Paulista e Votorantim, lutam para preservar a qualidade das águas da Represa Itupararanga, principal manancial de abastecimento público da região. Além de atender a população de alguns municípios que se localizam em seu entorno, o reservatório abastece também o Município de Sorocaba, que é o maior consumidor de suas águas, responsável pelo abastecimento de $63 \%$ da população da região. Desde a sua implantação, o Comitê estabeleceu como prioridade a transformação da área da represa em APA - Área de Proteção Ambiental. A APA de Itupararanga foi criada através da Lei 10.100/98, com o objetivo de proteger a diversidade biológica, disciplinar o processo de ocupação e assegurar a sustentabilidade do uso dos recursos naturais da Bacia da Represa. Seu perímetro foi ampliado pela Lei 11.579/03, passando a abranger os municípios de Ibiúna, Piedade, Votorantim, Vargem Grande Paulista, São Roque, Mairinque, Alumínio e o distrito de Caucaia do Alto. O território da APA possui 936,51 km², sendo que cerca de 29,9 km² ocupado com a represa.

Apesar da ótima qualidade de água observada na barragem de Itupararanga, este manancial se apresenta hoje sob sérios riscos ambientais devido ao uso e ocupação do solo. As ações voltadas à preservação da água, do solo, do ar, da fauna e da flora são ainda muito tímidas e insuficientes à intensidade e à velocidade da degradação. Há de se destacar que algumas iniciativas partidas do CBH-SMT, como a criação da Área de Proteção Ambiental, a realização desse estudo e a criação de um grupo gestor no âmbito do CBH-SMT, representam 
importantes ações frente aos aspectos negativos da degradação ambiental verificada nos últimos anos.

A represa de Itupararanga contribui para a formação dos rios Sorocaba, Sorocamirim e Sorocabuçu. $\mathrm{Na}$ área de drenagem destes dois últimos rios concentram, atualmente, os maiores problemas ambientais da região, principalmente os relacionados aos recursos hídricos. Seu uso agrícola é intensivo, e consta basicamente de pequenos proprietários (em média 4,5 alqueires) que se dedicam ao cultivo de morango, cebola, batata, tomate e outras olerícolas. Destacam-se os plantios intensivos próximos aos corpos de água sem a preocupação de práticas de conservação do solo, bem como a não observância do Código Florestal. A agricultura praticada na região é, na sua grande maioria, irrigada através de sistemas por aspersão. A fim de facilitar o manejo da cultura a tubulação do sistema de irrigação e os canteiros das hortaliças são, na maioria dos casos, dispostos "morro abaixo". Essa prática inadequada provocava carreamento dos horizontes superficiais do solo para os corpos de água, o que contribui para seu assoreamento, eutrofização e contaminação por pesticidas. A falta de um planejamento conservacionista das estradas vicinais existentes, também contribui para a erosão do solo. A atividade pecuária na região caracteriza por ser um sistema extensivo de baixa produtividade que pode ser aferida pela má conservação das pastagens. Estas por sua vez encontram-se infectadas, na sua maioria, por plantas invasoras. Outra grande ameaça aos recursos naturais da região é a especulação imobiliária, induzida por uma crescente valorização da terra devido a proximidade com a capital do Estado (SOS Itupararanga, 2009).

Com relação à urbanização, a cidade de Ibiúna se destaca como a maior aglomeração populacional dentro da área de drenagem da represa de Itupararanga. A margem esquerda da represa está sendo ocupada com maior intensidade, principalmente por chácaras isoladas, de diferentes tamanhos e padrões, e condomínios de alto padrão com vias asfaltadas, abrigos para embarcações do tipo lanchas e jet-ski.

Ibiúna é uma cidade localizada no interior de São Paulo, com economia baseada na agricultura e no turismo. Hoje com uma população de mais de 74 mil habitantes, é uma das 20 cidades de São Paulo que levam o título de "Estância Turística". Dos $1.093 \mathrm{Km}^{2}$ de Ibiúna, apenas de $10 \%$ é de zona urbana. Os outros $90 \%$ correspondem às áreas rurais de agricultura e pecuária de pequenos produtores e a áreas de preservação ambiental.

A escolha da microbacia piloto para início das atividades GT-PSA ponderou a importância dos projetos de PSA priorizarem as regiões com maior fragilidade socioambiental (previstas no plano de bacias) como é o caso das cidades de Ibiúna e Piedade, adicionada à relevância e potencial de geração de serviços ambientais, assim como na necessidade de mecanismos que viabilizem a restauração e conservação do ambiente.

Desse modo, dada a importância socioambiental do município de Ibiúna, para o início do programa de pagamentos por serviços ambientais os membros do GT-PSA escolheram por unanimidade a microbacia do Rio Murundú, compreendendo as principais nascentes do Rio Sorocabuçú, inserido na APA de Itupararanga.

A microbacia do ribeirão Murundú está localizado na sub-bacia 4 - Médio Sorocaba dentro da UGRHI 10. A Universidade Estadual Paulista, UNESP, campus Sorocaba, mantém um projeto de mapeamento e caracterização de nascentes e vegetação ciliar do ribeirão Murundú. Ao longo do estudo foram visitadas 127 nascentes, cerca de $90 \%$ das principais nascentes presentes na região. $\mathrm{O}$ estudo verificou ainda que, devido ao uso indevido do solo, principalmente pela remoção parcial ou total de vegetação, $15 \%$ das nascentes visitadas estavam secas. Das $85 \%$ restantes, $33 \%$ encontraram-se preservadas, $38 \%$ sofreram alguma forma de perturbação e $29 \%$ foram classificadas como degradadas. Os inúmeros trabalhos de campo permitiram originar mapas de uso e ocupação de solo, fragilidade ambiental e 
delimitação das áreas de preservação permanente, o quê facilitará a obtenção de informações para a valoração ambiental do programa.

\section{Próximas etapas}

As próximas etapas previstas são (i) a escolha e caracterização da propriedade onde será implantado o projeto piloto de pagamentos por serviços ambientais; (ii) a determinação do valor a ser pago por unidade de área (por hectare) ao proprietário rural como compensação pelos serviços ambientais fornecidos; e (iii) elaboração de indicadores ambientais que possam ser monitorados a fim de avaliar os benefícios ambientais do programa.

\section{Referências Bibliográficas}

CONSTANZA, R. Ecosystem services: If they're so important, why do we continue to abuse them? Fourth Henry Wallace Scientific Conference, 1-3 November 2005, CATIE, Turrialba, Costa Rica.

KAGOHARA, D.A. et al. Projeto Município Verde: Identificação e Caracterização do uso do solo na bacia do Ribeirão do Murundu, Ibiúna, São Paulo, Brasil. In.: VI SIMPÓSIO DE ENGENHARIA AMBIENTAL, Anais...maio de 2008 .

Rede das Águas. Disponível em: < http://www.rededasaguas.org.br/comite/comite_05.asp>. Acesso em: 1 out. 2009 .

SOS ITUPARARANGA. Caracterização geoambiental da bacia da represa de itupararanga, bacia hidrográfica do rio Sorocaba - SP. Disponível em: <http://www.sositupararanga.com.br/biblioteca/index.asp>. Acesso em: 1 out. 2009.

WWF. Payments for Environmental Services: An equitable approach for reducing poverty and conserving nature. $2006,18 p$. 